\title{
Social exclusion in families affected by paternal imprisonment
}

\begin{abstract}
Although social exclusion is often described as an outcome of paternal imprisonment, few studies have directly measured the extent of social exclusion in prisoners' families, or benchmarked it against the general population. This paper compares social exclusion among caregivers of children affected by paternal incarceration with overall estimates of social exclusion across the Australian population, and with estimates of social exclusion among a matched subset. Caregivers of children with imprisoned fathers were much more heavily excluded than adults in the general population. Compared to a matched sample, differences were smaller, and mostly related to inadequate financial resources. We propose that single parent status and financial hardship are key mediators of the relationship between paternal incarceration and social exclusion.
\end{abstract}

\section{Keywords}

Paternal incarceration, social exclusion, financial hardship, poverty, intergenerational effects of paternal imprisonment

\section{Suggested citation}

Besemer, K. L., \& Dennison, S. M. (2017). Social exclusion in families affected by paternal imprisonment. Australian \& New Zealand Journal of Criminology (advance online publication), doi:10.1177/0004865817701530 


\section{Introduction}

Social exclusion of children of prisoners and intergenerational social inequality have emerged as outcomes of an era of mass incarceration in the United States (Foster \& Hagan, 2015, in press; Wildeman \& Wakefield, 2014). As most imprisoned men are fathers, increasing imprisonment rates are thought to place growing numbers of children at risk (Geller, Garfinkel, \& Western, 2011). With substantial longterm human and societal costs associated with exclusion and inequality, policies protecting these children from a cycle of disadvantage could have far-reaching impacts.

However, research on the specific social exclusionary effects of paternal imprisonment is lacking in comparison to research directed towards the behavioural, mental health and offending outcomes of prisoners' children. Furthermore, rather than measuring social exclusion directly, studies in this area typically use proximate measures of social exclusion such as low income, homelessness and unemployment (e.g. Foster \& Hagan, 2007; Murray, 2007). Recently, Foster and Hagan (2015) proposed that inequality and social exclusionary outcomes for prisoners' children are directly impacted by paternal imprisonment, but also indirectly impacted through a number of mediating factors previously considered to be direct outcomes of paternal incarceration (i.e., children's educational outcomes, emotional and behavioural problems, social psychological factors, and family resources and processes). These proposed mediating pathways to children's inequality and social exclusion are yet to be empirically tested.

Using data collected from 34 caregivers, with a total of 78 children, we examine whether paternal incarceration is associated with greater social exclusion in families of prisoners living in Queensland (Australia) compared to (1) the general Australian population and (2) a matched household sample. Building on Foster and Hagan's (2015) multilevel framework for the study of the effect of parental incarceration on child inequality and social exclusion, we focus specifically on the impact of paternal incarceration on the social exclusion of caregivers of children with incarcerated fathers. We also consider the ways in which caregiver social exclusion may mediate the social exclusion of children in the 
household. By using a narrower definition of social exclusion that can be measured more directly, we are able to consider likely risk factors and causal mechanisms of social exclusion separate from its outcomes.

\section{Social exclusion - definitions}

Although the term social exclusion itself is recent, concerns about individuals requiring access to a 'decent life', including not only physiological functioning but also 'valued activities', can be traced back as far as Aristotle (Sen, 2000). In the $18^{\text {th }}$ Century, Adam Smith expanded the concept of social requirements by recognising that every society has items that are "indecent for creditable people, even of the lowest order, to be without” (Smith, 1776 / 1999); these requirements are contextually dependent and changeable over time. In the $20^{\text {th }}$ Century, Townsend's seminal definition of poverty combined the contextually dependent social requirement for material possessions with Aristotle’s 'valued activities' (Townsend, 1979). This focus on social expectations has become the basis of most widely used concepts of social exclusion. For example, Burchardt, Le Grand, and Piachaud (2002, p. 32), defined people as excluded if "he or she does not participate in the key activities in the society in which he or she lives". Other common definitions combine a lack of participation in key activities with a lack of access to customary living conditions, sometimes also including measures of labour market exclusion and service exclusion (e.g. Pantazis, Gordon, \& Levitas, 2006; Saunders, Naidoo, \& Griffiths, 2008; Scutella, Wilkins, \& Horn, 2009).

For the purposes of this study, we identified people as excluded if they lacked access to the activities and living conditions that are customary in the society in which they live. Though otherwise similar to Burchardt et al. (2002), our operational definition differs by combining customary living conditions, as measured by common possessions, with participation in social life, including social participation and service use. This decision was based on two key insights. First, in recognition of the profound effect material possessions may have on the experience of social participation (Smith, 1776 / 
1999), we argue that a comprehensive definition of social exclusion needs to combine both social participation and a basic acceptable living standard. At the same time, by avoiding a more complex set of additional components such as labour market participation and low income, we maintain a conceptual separation between the concept of social exclusion and its associated risk factors, causal mechanisms and consequences (Hobcraft, 2002).

\section{Social exclusion and paternal incarceration}

There are few studies that have examined social exclusion in the context of paternal incarceration specifically. Foster and Hagan (2007), defining social exclusion as 'being shut out from conventional society', measure a combination of homelessness, lack of health care coverage and an absence of political participation in the United States. In the United Kingdom, Murray (2007) proposed a variety of components of social exclusion, including administrative exclusion, stigma, constraints on visitation, lack of political engagement and pre-existing disadvantage. In their recent study of parental imprisonment and the social exclusion of offspring in young adulthood, Foster and Hagan (in press) focus on socio-economic inequality as an indicator of social exclusion by assessing personal and household income, perceived socio-economic status and feelings of powerlessness. A recent study on social exclusion of prisoners' children in the United States focused on material hardship and exclusion from medical care (Sykes \& Pettit, 2015). Broadly speaking, on most of the social exclusion indicators measured, children and caregivers affected by paternal incarceration were found to be disadvantaged. As suggested by Sykes and Pettit (2015), the American criminal justice system, which is both highly stratified by race and class and characterised by almost unparalleled imprisonment rates, may form a context in which the social exclusion risks of paternal incarceration are especially high. The high levels

of social exclusion found in American prisoners' families may thus be due to the very high concentrations 
of imprisonments in a subgroup of already disadvantaged communities. These circumstances may be quite different in the Australian context.

A number of qualitative studies have described behaviours and effects that are suggestive of social exclusion in a narrower definition, without using the concept itself. For instance, Bocknek, Sanderson, Britner, and Preston (2009, p. 328) describe children with imprisoned relatives as "feeling isolated and different from those around them” leading them to avoid contact with others. A much wider range of studies have reported on mechanisms that are likely to relate to social exclusion (see Foster \& Hagan, 2015 for a comprehensive review), as well as on social inequality more widely (Turney, 2014). Most recently, Foster and Hagan (2015) built on existing research on the effects of maternal and paternal imprisonment on children and drew on ecological and life course perspectives to develop a comprehensive "multilevel framework for the study of regimes and parental incarceration and their effects on child inequality and social exclusion” (p. 137). At the macro level the authors propose state and cross-national regimes are either exclusionary (e.g., state termination of parental rights) or inclusionary (e.g., state welfare supports) in their functions and exacerbate or reduce the social exclusion of children. At the meso level, schools regimes, including school policies and delinquency levels, are impacted by macro level factors that then have direct effects at the micro level on child social exclusion but also on proposed mediating influences. These mediating factors include education, emotional and behavioural problems, family resources and processes and social psychological factors. The authors intend the multilevel framework to be developed through further research and theory testing.

We take this framework as a starting point to explore the potential mediating factors between paternal incarceration and social exclusion in children and caregivers. As Foster and Hagan (2015) illustrate, prisoners’ relatives are likely to be vulnerable to social exclusion through a combination of interacting circumstances, including macro-level influences such as exclusions arising from national policy, as well as more immediate effects at the household, school and neighbourhood level. Although the 
contribution of each of these factors to social exclusion has not yet been studied, other research in paternal imprisonment has identified a range of potential outcomes of paternal imprisonment that are likely to be related, or are known to be related to social exclusion.

A number of authors have pointed out that some of the exclusionary consequences of paternal imprisonment may be transmitted through children’s remaining caregiver. Typically this caregiver is the child’s mother (Maruschak, Glaze, \& Mumola, 2010), but it is likely that other caregivers may be similarly impacted. Quantitative research shows that paternal incarceration is associated with elevated levels of life dissatisfaction in mothers, as well as a heavily increased risk of a major depressive episode (Wildeman, Schnittker, \& Turney, 2012). Depression is strongly associated with loneliness and withdrawal from social contact, and depressive symptoms may impair the quality of social interactions and activities, thus resulting in the social exclusion of affected adults. Self-exclusion of adult caregivers may also reduce the extent to which children participate in social activities.

Depression risks to caregivers may be exacerbated by stress arising from sudden income losses and material hardship associated with paternal incarceration (Hagan \& Dinovitzer, 1999; Murray \& Farrington, 2008; Schwartz-Soicher, Geller, \& Garfinkel, 2011), as well as by the transition from a twoparent into a single parent household (Targosz et al., 2003). Many social activities have costs directly associated with them, including transport, food and drinks, or entrance fees. In addition, many social activities require material possessions, such as appropriate attire. Families may also experience social exclusion as a consequence of social stigma. Existing qualitative studies strongly suggest a relationship between the experience of stigmatisation and various types of social exclusion, including disengagement (authors, under review; Beck \& Jones, 2008; Braman, 2004; Dawson, Jackson, \& Nyamathi, 2012; Nesmith \& Ruhland, 2008; Shlafer \& Poehlmann, 2010).

Finally, contemporaneous risk factors associated with paternal imprisonment likely interact with pre-existing risk factors for social exclusion such as a prisoners' history of unemployment, lack of basic 
skills, mental health problems, substance abuse, marital problems, childhood experiences of abuse and neglect and a household history of severe material hardship (Geller, Garfinkel, Cooper, \& Mincy, 2009; Murray \& Farrington, 2008; Schwartz-Soicher et al., 2011; Social Exclusion Unit, 2002). In Australia, children are more likely to have experienced insecure housing situations prior to paternal imprisonment, and are much more likely to be Indigenous, both of which are statistically associated with higher risks of poor developmental outcomes, independent of incarceration (Dennison, Stewart, \& Freiberg, 2013).

\section{Hypotheses}

The purpose of this study is to examine the extent to which the children of incarcerated fathers live in households experiencing greater social exclusion than similar households that have not been affected by incarceration. To this end, a sample of caregivers of children affected by paternal incarceration was compared to (1) the general Australian population, and (2) a matched sample with a similar household composition. Although we are unable to study all the potential mediating mechanisms identified by Foster and Hagan (2015), their framework forms a useful starting point for our analysis. First, due to the proposed effect of paternal incarceration on family resources and processes, we expect social exclusion in caregivers to be higher than that of families in the general population (Hypothesis 1). As we hypothesise that paternal incarceration increases social exclusion risks, we would expect caregivers to be experiencing greater social exclusion than a matched sample of households with a similar composition (Hypothesis 2).

\section{Methods}

Data

The analysis was drawn from two datasets. The first dataset, referred to as VF dataset was collected as part of the Vulnerable Families Project, a research project that examines the impact of paternal 
imprisonment on children, their caregivers, and the imprisoned father. The VF data used in this paper comprises of households in which at least one child has a father, or father figure (e.g., step-father for at least 12 months), who was imprisoned in Queensland, Australia at the time of the survey.Estimates for the general population and for the matched subsample were drawn from the Poverty and Exclusion in Modern Australia (PEMA) survey (Saunders \& Wong, 2010).

For the VF survey, caregivers were recruited through a combination of methods. Flyers were placed and circulated in prison waiting areas, prison transport buses, and through agencies that were likely to be working with families in the target population (i.e., church and welfare agencies, prison ministries and fellowships). Furthermore, advertisements were placed in a prison newsletter for inmates. The lead researcher also made two appearances on a community radio program for prisoners and families. Caregivers were administered a survey (approx. 60 mins) and took part in a semi-structured interview (approx. 90 mins). Caregivers were provided with an $\$ 80$ supermarket voucher. Most interviews and surveys were undertaken in person, but some were conducted over the phone due to the barriers of distance (i.e., lived more than a two hour radius from the university). Recruitment took place from 2010 2014. Griffith University’s Human Research Ethics Committee approved the study.

The resulting dataset comprised of 34 caregivers (33 of whom were female), with a total of 78 children. Children were between three months and 17 years old $(M=6.8, S D=5)$. Children were included if their caregiver indicated that the child considered the imprisoned male to be a father. The majority of children's fathers had been imprisoned for less than two years (71\%), with $6 \%$ imprisoned for between two and five years and $18 \%$ imprisoned for more than five years ( $6 \%$ unknown). Nearly half of the caregivers were in a relationship with the prisoner and another 9\% were still married to the prisoner (see Table 1). Though not shown in Table 1, of those caregivers not in a relationship to the prisoner, four caregivers (12\%) were grandparents of the study children.

Table 1 
The PEMA dataset is a nationally representative dataset, derived from postal surveys undertaken by the Social Policy Research Centre. The PEMA survey was distributed by mail to 6000 adults drawn at random from the electoral rolls in May 2010. It generated 2645 responses - a response rate of 46.1 percent. Although broadly representative, systematic differences in response rates resulted in an underrepresentation of some groups, including the lowest and highest income groups, Indigenous people and private renters (Saunders \& Wong, 2011, 2014).

The PEMA Survey included a set of social exclusion and deprivation questions which were replicated in the VF survey. This set of questions identified 73 items, such as 'a substantial meal at least once a day' and 'regular social contact with other people'. The PEMA survey identified 24 of these items as ‘essential’ by a majority of those surveyed (Saunders \& Wong, 2012, 2014).

Analysis

Social exclusion of both adults and children is defined as a lack of access to the activities and living conditions that are customary in the society in which they live. Operationalising this definition requires, first, the selection of activities and living conditions that are 'customary' in Australia, and second, whether the individuals studied lack access to these customary items. Using the consensual method devised by Mack and Lansley (1985), Saunders and others (Saunders, 2011; Saunders \& Naidoo, 2009; Saunders et al., 2008; Saunders \& Wong, 2014) operationalized social exclusion in relation to a list of key activities, services and capacities that a majority of the population defined as 'essential' in Australia. We broadly follow the system of selecting social exclusion indicators as proposed by Saunders et al. (2008). Thus, items were selected because they were considered 'essential' by more than $50 \%$ of the PEMA sample, or because Saunders et al. originally selected them as indicators of social exclusion on the basis that a majority of the Australian population, across all age groups, engage in these activities. Some economic indicators were excluded, as they did not fit with our definition of social exclusion, and did not 
take the form of a deprivation of a consensually defined essential possession or activity. Items such as 'currently unemployed' and 'living in a jobless household' were excluded on these grounds. Instead, an additional dimension of social exclusion relating to essential living conditions was added, in keeping with the definition of 'ordinary living patterns' as well as activities. In line with Saunders (2008), we measured social exclusion as indicated by a lack of an essential item, regardless of the stated reason for this lack.

We thus identify three main components of social exclusion: (1) Living Conditions: A lack of ordinary possessions regarded as essential by the majority of the population; (2) Disengagement: A lack of participation in common social and community activities; and (3) Service Exclusion: A lack of access to adequate commonly used services.

It is explicitly acknowledged that non-participation in activities may be, to an extent, reflective of a difference in preferences and choices, rather than a lack of access. The inability to distinguish between a true lack of access and this preferential diversity potentially results in an overestimation of social exclusion. Nonetheless, as the number of instances of non-participation in customary activities and living patterns increase, exclusion becomes increasingly likely (Saunders, 2011), especially if high levels of non-participation are accompanied by other indicators suggesting impacted well-being.

In order to contextualise the social exclusion of prisoners' families, indicators in the survey were benchmarked against general population figures. For these, we used the percentages reported from the PEMA Survey. In addition, a matched sample was drawn from the PEMA population in order to better reflect the demographic characteristics of the VF dataset. Propensity score matching is a commonly used tool to adjust for confounding variables in studies where the population of interest, i.e. 'the treatment group', is non-randomly selected, and where the variables which determine the likelihood of selection into the ‘treatment group’ are likely to influence the measured outcome (Heinze \& Juni, 2011). As the matched sample resembles the demographic composition of the VF data much more closely, it can provide a much better estimate of the effects of family incarceration. 
The matched sample was restricted to households with at least one resident child. In the VF dataset, this was so for all 34 cases. Of the 2645 PEMA cases, 776 remained. For each case in both datasets, a propensity score was calculated using binary logistic regression. The propensity score expresses a conditional probability that any participant is a member of the 'treatment group', in this case the VF dataset.

Variables used to calculate the propensity score were chosen because they were associated with a risk of familial incarceration and/or inclusion in the VF dataset, but were not likely to be affected by familial incarceration - typically, such variables are chosen because they are reasonably constant over time (Caliendo \& Kopeinig, 2008; Thoemmes \& Kim, 2011). Tenure, marital status and subjective poverty were rejected because they likely relate to incarceration. Prior to inclusion, bivariate relations between potential covariates and treatment assignment were examined. In the absence of a significant result at $\mathrm{p}<0.05$ in a bivariate model, area deprivation was excluded. In addition, only those predictors that remained significant when controlling for other predictors, as determined by logistic regression, were included, with the rationale that only the remaining predictors could add anything significant to the predicted score. On this basis Indigenous status was also excluded as a matching variable.

The selected variables on which households were matched were the number of adults and children, age, gender and employment status of the respondent. The number of adults was retained despite its association with incarceration, because this would allow the researchers to differentiate between social exclusion resulting from familial incarceration and that resulting from single parenthood.

Each case in the VF data was matched to two cases in the PEMA dataset with the closest propensity score, using 1:2 nearest neighbour matching with replacement. In order to avoid losing cases from the much smaller VF dataset, no caliper was set. This resulted in a matched dataset of 37 unweighted cases. Matching weights ranged from 0.5 to 3.8, with a mean of 1 . As can be seen in Table 2, the matched sample was very similar to the VF data with regard to the matching variables. 
Table 2

\section{Results and Discussion}

In general, caregivers of children with imprisoned fathers were much more heavily excluded than the general population. This exclusion extended to most indicators relating to inadequate living conditions, disengagement from normal social activities and lack of access to basic services. When compared to the matched sample, the picture was more complex. This section will first examine the pattern of social exclusion within each component. Subsequently, we will consider overall patterns of exclusion.

\section{Living conditions}

As can be seen in Table 3, one of the living condition indicators on which the VF caregivers most clearly differed from either the matched sample or the general population, was that of emergency savings. Caregivers were much more likely to lack the relatively small amount of \$500AUD in savings. Such savings are considered essential by more than $80 \%$ of Australians (Saunders \& Wong, 2012), and deprivation is therefore a severe form of social exclusion. Indirectly, a lack of savings may also have implications for other forms of social exclusion, for example, by restricting families’ ability to take part in customary celebrations such as Christmas, which may require savings for special foods and gifts (Dolphin, 2009). In addition, an absence of a financial cushion may result in a much greater vulnerability to shocks, so that any unexpected expenses, such as a broken fridge, may threaten the immediate wellbeing of the household and its members, and may force households into problematic levels and types of debt (Dolphin, 2009; Lister, 2006).

Table 3

Ownership of a landline telephone was considerably lower for the caregivers in the VF sample, compared to both the matched sample and the general population. In themselves, telephones are considered essential by almost $60 \%$ of Australians, and deprivation thus indicates social exclusion 
(Saunders \& Wong, 2011, 2012). In the VF sample, households without a landline all owned at least one mobile. However, households reliant on a mobile phone may be more likely to restrict use because of higher costs and access may be restricted to particular household members. Lack of a landline telephone may also constrain contact with the incarcerated parent, as prisons typically charge much higher rates to calls to mobile phones. Other studies have found that such costs may have a substantial effect on households’ finances and can severely limit families’ contact with imprisoned relatives (Braman, 2004; Christian, Mellow, \& Thomas, 2006; Dennison \& Smallbone, 2015; Shlafer \& Poehlmann, 2010).

Cars are italicised in Table 4 because only 45\% of the population considered it 'essential' for life in Australia, and it thus narrowly failed to meet the threshold for a social exclusion indicator (Saunders \& Wong, 2012). Nonetheless, car ownership may be instrumental to other forms of exclusion. An inability to travel easily may deter people from using public services, including medical services, and may also affect social participation, for example with regard to the ability to visit friends and family (Bramley \& Besemer, 2011). As can be seen in Table 5, caregivers were much more likely to indicate that they have lacked transport to an important event than both the matched sample and the general population, suggesting a link between caregivers’ car ownership and their ability to participate socially. For caregivers living in areas poorly serviced by public transport, lack of car ownership may also impact on caregiver's ability to bring children to visit their fathers.

On a second group of indicators, caregivers and the matched sample were clearly more excluded than the general population, but no significant differences were found between the two groups. Both the VF sample and the matched sample are small, and it is likely that the relative rarity of these deprivations required larger samples to observe differences. Nonetheless, differences with the overall populations are indicative. Holidays away from home are considered essential by over half of the Australian population. For children and adults, an inability to experience holidays and share holiday stories thus forms a type of exclusion from normal Australian life. Qualitative research in the United Kingdom showed that for 
children, the impact of missing out on holidays was not only in the holiday itself, but was felt though social comparison with peers, who were able to anticipate and subsequently relate memories of holidays with their families. Children who did not have such holidays reported feeling of different and left behind (Ridge, 2002).

Exclusions relating to adequate meals and inadequate furniture were relatively unusual, and the small sample sizes did not allow for the identification of differences with the matched sample. Even so, it is concerning that even a minority of the caregivers did not eat a substantial meal each day. Food insecurity represents a very serious deprivation, and poses substantial threats to long-term health. These problems may extend directly to children. A 2012 Australian survey found that almost 80 per cent of children living in food-insecure households experienced some form of food insecurity themselves, even though adults went to significant lengths to protect their children from the worst effects of hunger and inadequate nutrition. The same study found that food insecurity also had major implications for other aspects of social exclusion, as parents without adequate food in the house were unable to allow children to invite friends over and restricted children's involvement in recreational activities (Anglicare Australia, 2012).

\section{Disengagement}

As demonstrated in Table 4, for almost all indicators relating to social disengagement, there were no major differences between caregivers and the matched sample, but major differences with the general population. Like households in the matched dataset, the VF caregivers were heavily excluded in their ability to attend weddings and funerals or go out with friends. Such differences may be indicative of the financial difficulties faced by single parent households who are not in employment, including problems in accessing affordable childcare.

Table 4 
Interestingly, caregivers in the VF sample were most likely to be involved in community activities. While it is possible that community activities are used as a strategy to help families cope with other forms of disadvantage, it is also possible that because many families were recruited through agencies that were working with the target population, more community-involved households were selected.

No significant differences were found with regard to regular social contact or presents for friends and family. It is possible that the parents in both the VF and matched sample, though clearly excluded from contacts with friends, may have had more casual social contact through children's activities. Christmas presents are sometimes provided through charitable foundations, which may help mitigate difficulties some families have providing them otherwise. However, it was surprising to observe that there were also no clear differences in acceptance and respect from others, which might have been thought to be related to social stigma, although the small numbers in the VF and matched sample mean no conclusions can be drawn from these null findings.

\section{Service Exclusion}

With regard to service exclusion, no significant differences were found between the VF sample and the matched sample, and few indicators showed significant differences with the general population (see Table 5). However, the indicators nevertheless showed very severe levels of exclusion. Almost a quarter of the VF sample was unable to buy prescribed medications, which represent an almost unanimously agreed necessity: by 99\% of Australians. In addition, the majority of the VF sample lacked access to necessary dental treatment, considered essential by $98 \%$ of Australians (Saunders \& Wong, 2012). There are clear implications of these deprivations for long-term health, but there may also be additional indirect effects on social exclusion. Dental problems, such as tooth loss, have been linked to social isolation, depression, mental health problems, morbidity and mortality (Besemer \& Bramley, 2012; Coles et al., 2011; McGrath 
\& Bedi, 2002; Watt \& Sheiham, 1999). Such problems in caregivers are likely to impact on children. In addition, the level of health service-related exclusion seen in caregivers would suggest that children may also be more likely to experience health service exclusions themselves.

Table 5

Some services showed no significant differences between the three samples. Access to local hospitals and bulk billing doctors may be ensured for vulnerable populations through the generally good standard of public health care in Australia. Conversely, access to mental health and childcare, both essential items, appear to be uniformly problematic in all three groups.

One of the starkest differences in service exclusion was found for utility bills, where more than half of the VF sample had struggled with gas, water or electricity payments. An inability to keep up with bills is a commonly used indicator of financial hardship. From a social exclusion perspective, utility disruptions resulting from unpaid bills may preclude a basic acceptable living standard. They are also likely to have an immediate, noticeable effect to children, and to be traumatic events in children's lives. In the US, utility disruptions were found to cause subsequent externalising behavioural problems in children (Zilanawala \& Pilkauskas, 2012).

\section{Summary}

The social exclusion indicators discussed above differed in the extent to which they were related to financial hardship and poverty. The overall pattern of responses suggested that the areas where the VF sample was most heavily excluded were also those where a lack of adequate financial resources was most likely to be a contributing factor. The extent of exclusion in living conditions was far greater than the extent of differences in disengagement and service exclusion. Exclusions in disengagement were concentrated among those items where the respondent identified money as the reason for exclusion (e.g. 
going out with friends and paying one's way). Similarly, exclusions in services were found in those services that have an immediate cost attached - prescriptions are usually subsidised but not fully covered by Australia’s public health system and dental care was not covered at the time of the survey.

\section{Limitations}

Paternal incarceration research has a number of inherent methodological challenges. First, given that affected families are largely found within the most disadvantaged populations, it is difficult to overcome problems associated with selection bias (Wildeman, 2014). As this study used propensity score matching to adjust for observable non-equivalence identified between the sample of caregivers of prisoners' children and the general population, we were able provide a much better estimate of the extent to which paternal incarceration impacts on social exclusion than could have been provided with a general population benchmark alone. However, only observable non-equivalence can be compensated in this way. As with any study using propensity score matching, it should be acknowledged that the extent to which the populations could be matched is always limited by the availability of variables common to both datasets (see Caliendo \& Kopeinig, 2008).

A second problem is the difficulty associated with recruiting participants for paternal incarceration research. Family members of prisoners are notoriously reluctant to come forward for research, not only because such families often have many pressing needs and preoccupations that take priority over research involvement but also because of the social stigma associated with family imprisonment (Easterling \& Johnson, 2015). The 34 caregivers who took part in this study were recruited over a three-and-a-half year period, using a wide variety of methods of recruitment. The smallness of the resulting sample, despite these efforts, highlights the extent to which the needs of this population may continue to be hidden. Given that this is a difficult-to-reach population, it is quite possible that those 
caregivers who were successfully contacted and recruited were in fact the least socially excluded. The true rate of social exclusion in this population may therefore be higher than we were able to measure.

Finally, differences in fieldwork methodology may have potentially affected the validity of comparisons between the datasets. The PEMA Survey was a postal survey, and therefore completed privately and anonymously by the participants, whereas for the VF survey, questions were read out loud. Given that many of the items were quite factual, such as the ownership of cars or telephones, it is unlikely that answers were substantially affected by the method of administration.

\section{Conclusion}

This paper compared a nationally representative dataset with a sample of caregivers of children with an imprisoned father in Queensland. We formulated two hypotheses. We can confirm our first hypothesis, in that the caregivers of prisoners' children were found to be more socially excluded than adults in the general population on most indicators. These differences were statistically significant and extended to all three components of social exclusion, though fewer differences were found in disengagement and service exclusion than in material living conditions. We found some support for our second hypothesis, that the caregivers of children whose fathers are imprisoned would be more socially excluded than other parents in a matched sample. When compared to a sample of parents with comparable household sizes, numbers of children, age and employment status of caregivers, the differences in social exclusion were smaller. Nonetheless, the families of prisoners performed significantly worse than the matched sample on some indicators of social exclusion, particularly those exclusions which are directly related to inadequate financial resources.

The overall association between paternal incarceration and social exclusion found in this study is consistent with previous US-based studies in this area. Nonetheless, minor dissimilarities in results are indicative of noteworthy contextual differences. For instance, contradictory to our Australian findings, 
Sykes and Pettit's (2015) propensity score matching model showed paternal and maternal incarceration to be associated with unmet health needs and greater health service utilisation. This difference may be reflective of the more comprehensive Australian health care system.

Despite major contextual differences and differences in constructs and measurements, we found that like in the United States, the social exclusion of Australian caregivers' of children affected by paternal incarceration is severe. We propose two potential mechanisms mediating the relationship between paternal incarceration and social exclusion. First, caregivers in the Vulnerable Families study had lost a spouse through imprisonment, thus effectively becoming single parents. As single parents, these caregivers became part of one of the most socially and economically disadvantaged groups in Australia (Grahame \& Marston, 2011; Wilkins, 2015). The level of social exclusion experienced by the matched sample confirmed the vulnerability of households with higher rates of unemployment and a lower average number of adults.

The second mechanism that may mediate the relationship between incarceration and social exclusion is financial hardship. Many of the forms of social exclusion affecting families of prisoners most severely, related to items suggestive of an inadequate command of financial resources. Future research, using longitudinal datasets, may be able to determine the extent to which paternal incarceration directly impacts on households' disposable income, and how such effects may subsequently cause social exclusion of adults and children in families. In addition, future research might compare the extent of social exclusion in households where incarceration occurred before and after the birth of children. Recent research has shown that paternal incarceration is only a significant risk for offspring incarceration if it occurs after the child's birth (Dennison, Bijleveld, \& van de Weijer, 2017 forthcoming). There is also a need for research incorporating more specific children’s social exclusion items, relating to social disengagement, deprivation of essential possessions and exclusion from customary activities. Such population indicators are not yet available in Australia. 
Social exclusion may not only be a negative outcome of paternal imprisonment, but may additionally mediate other negative health and wellbeing impacts associated with paternal incarceration, including long-term effects on children. As described in this paper, many of the social exclusions that more heavily affected caregivers in prisoners' families are also known to have detrimental effects on the healthy development of children; and on children's outcomes in adulthood. Indeed, beyond social exclusion as an outcome in itself, structural disadvantage has been demonstrated to reduce parental efficacy, increase harsh and inconsistent parenting practices, subsequently creating risks for delinquency and adolescent offending (Sampson \& Laub, 1995; Thornberry \& Krohn, 2001, 2005).

However, aside from the potential long-term effects of social exclusion on other child well-being outcomes, social exclusion in prisoners' families should in itself be regarded as a substantial immediate threat to children and adult's wellbeing. International research has shown that being unable to 'fit in' and ‘join in’ with others is associated with intense anxiety, insecurity and humiliation, and may cause enduring psychological harm to adults and children alike (Payne, 2006; Ridge, 2002, 2006, 2009). From a policy perspective, the promotion of greater inclusion of prisoner's families could thus have a substantial immediate and long-term positive impact on this especially vulnerable group. 


\section{Bibliography}

Anglicare Australia. (2012). When there's not enough to eat. Retrieved from Ainslie, ACT:

https://www.anglicare.org.au/sites/default/files/public/Anglicare WTIET E VOLUME\%202\%20FA.pdf

Beck, E., \& Jones, S. J. (2008). Children of the Condemned: Grieving the Loss of a Father to Death Row. OMEGA - Journal of Death and Dying, 56(2), 191-215. doi:10.2190/OM.56.2.d

Besemer, K., \& Bramley, G. (2012). Local Services Under Siege; attitudes to public services in a time of austerity. Poverty and Social Exclusion in the UK. Working Paper Analysis Series(2).

Bocknek, E. L., Sanderson, J., Britner, I. V., \& Preston, A. (2009). Ambiguous loss and posttraumatic stress in school-age children of prisoners. Journal of Child and Family Studies, 18(3), 323-333.

Braman, D. (2004). Doing time on the outside: Incarceration and family life in urban America: University of Michigan Press.

Bramley, G., \& Besemer, K. (2011). Access to Public and Private Services in the PSE Survey (4). Retrieved from Bristol: http://www.poverty.ac.uk/methodsworking-papers-local-services-means-testing-inequality-deprivationfinancial-exclusion

Burchardt, T., Le Grand, J., \& Piachaud, D. (2002). Degrees of exclusion: developing a dynamic, multidimensional measure. In P. Agulnik (Ed.), Understanding social exclusion. Oxford: Oxford University Press.

Caliendo, M., \& Kopeinig, S. (2008). Some practical guidance for the implementation of propensity score matching. Journal of economic surveys, 22(1), 31-72.

Christian, J., Mellow, J., \& Thomas, S. (2006). Social and economic implications of family connections to prisoners. Journal of Criminal Justice, 34(4), 443-452.

Coles, E., Chan, K., Collins, J., Humphris, G. M., Richards, D., Williams, B., \& Freeman, R. (2011). Decayed and missing teeth and oral-health-related factors: Predicting depression in homeless people. Journal of Psychosomatic Research, 71(2), 108-112.

Dawson, A., Jackson, D., \& Nyamathi, A. (2012). Children of incarcerated parents: Insights to addressing a growing public health concern in Australia. Children and Youth Services Review, 34(12), 2433-2441. doi:http://dx.doi.org/10.1016/i.childyouth.2012.09.003

Dennison, S., \& Smallbone, H. (2015). 'You Can't Be Much of Anything from Inside': The Implications of Imprisoned Fathers' Parental Involvement and Generative Opportunities for Children's Wellbeing. Law in Context, 32(1). 
Dennison, S., Stewart, A., \& Freiberg, K. (2013). A prevalence study of children with imprisoned fathers: annual and lifetime estimates. Australian Journal of Social Issues, 48(3), 339-361.

Dennison, S. M., Bijleveld, C., \& van de Weijer, S. (2017 forthcoming). Intergenerational Continuity in Incarceration: Evidence from a Dutch multigeneration cohort. In A. Blokland \& V. van der Geest (Eds.), The Routledge International Handbook of Life-Course Criminology. London, United Kingdom: Taylor \& Francis Ltd.

Dolphin, T. (2009). Saving and asset-building in low-income households. Institute for Public Policy Research.

Easterling, B. A., \& Johnson, E. I. (2015). Conducting Qualitative Research on Parental Incarceration: Personal Reflections on Challenges and Contribution. The Qualitative Report, 20(10), 1550.

Foster, H., \& Hagan, J. (2007). Incarceration and intergenerational social exclusion. Social Problems, 54(4), 399-433. doi:10.1525/sp.2007.54.4.399

Foster, H., \& Hagan, J. (2015). Punishment Regimes and the Multilevel Effects of Parental Incarceration: Intergenerational, Intersectional, and Interinstitutional Models of Social Inequality and Systemic Exclusion. Annual Review of Sociology, 41(1), 135-158. doi:doi:10.1146/annurev-soc073014-112437

Foster, H., \& Hagan, J. (in press). Maternal and Paternal Imprisonment and Children's Social Exclusion in Young Adulthood. Journal of Criminal Law and Criminology.

Geller, A., Garfinkel, I., Cooper, C. E., \& Mincy, R. B. (2009). Parental Incarceration and Child Well - Being: Implications for Urban Families. Social science quarterly, 90(5), 1186-1202.

Geller, A., Garfinkel, I., \& Western, B. (2011). Paternal Incarceration and Support for Children in Fragile Families. Demography, 48(1), 25-47. doi:10.1007/s13524-010-0009-9

Grahame, T., \& Marston, G. (2011). Welfare-to-work Policies and the Experience of Employed Single Mothers on Income Support in Australia: Where are the Benefits? Australian Social Work, 65(1), 73-86. doi:10.1080/0312407X.2011.604093

Hagan, J., \& Dinovitzer, R. (1999). Collateral consequences of imprisonment for children, communities, and prisoners. Crime and Justice, 26, 121-162.

Heinze, G., \& Juni, P. (2011). An overview of the objectives of and the approaches to propensity score analyses. European heart journal, 32(14), 1704-1708. doi:10.1093/eurheartj/ehr031 
Hobcraft, J. (2002). Social exclusion and the generations. In J. Hills, J. Le Grand, \& D. Piachaud (Eds.), Understanding social exclusion (pp. 62-83). Oxford: Oxford University Press.

Lister, R. (2006). Poverty, material insecurity, and income vulnerability: the role of savings. S Sodha and R Lister, The Saving Gateway: From Principles to Practice, ippr, 8-33.

Mack, J., \& Lansley, S. (1985). Poor Britain. London: George Allen \& Unwin. Maruschak, L., Glaze, L., \& Mumola, C. (2010). Incarcerated Parents and their Children: Findings from the Bureau of Justice Statistics In J. M. Eddy \& J. Poehlmann (Eds.), Children of Incarcerated Parents - A Handbook for Researchers and Practitioners (Vol. 2, pp. 33-54). Washington: The Urban Institute Press.

McGrath, C., \& Bedi, R. (2002). Population based norming of the UK oral health related quality of life measure. British Dental Journal, 193(9), 521-524.

Murray, J. (2007). The cycle of punishment: Social exclusion of prisoners and their children. Criminology and Criminal Justice, 7(1), 55-81. doi:10.1177/1748895807072476

Murray, J., \& Farrington, D. P. (2008). Parental imprisonment: long-lasting effects on boys' internalizing problems through the life course. Development Psychopathology, 20(1), 273-290. doi:10.1017/S0954579408000138

Nesmith, A., \& Ruhland, E. (2008). Children of incarcerated parents: Challenges and resiliency, in their own words. Children and Youth Services Review, 30(10), 1119-1130.

Pantazis, C., Gordon, D., \& Levitas, R. (2006). Introduction. In C. Pantazis, D. Gordon, \& R. Levitas (Eds.), Poverty and social exclusion in Britain (pp. 1-25). Bristol: University of Bristol.

Payne, S. (2006). Mental health, poverty and social exclusion. In C. Pantazis, D. Gordon, \& R. Levitas (Eds.), Poverty and social exclusion in Britain (pp. 285311). Bristol: University of Bristol.

Ridge, T. (2002). Childhood poverty and social exclusion: From a child's perspective: Bristol: Policy press.

Ridge, T. (2006). Childhood poverty: a barrier to social participation and inclusion. Children, Young People and Social Inclusion: Participation for What, 23-38.

Ridge, T. (2009). Living with poverty. A review of the literature on children's and families' experiences of poverty (594). Retrieved from Norwich:

Sampson, R. J., \& Laub, J. H. (1995). Crime in the making: Pathways and turning points through life: Harvard University Press.

Saunders, P. (2008). Measuring wellbeing using non-monetary indicators: Deprivation and social exclusion. Family Matters, 78, 8-17. 
Saunders, P. (2011). Down and out: poverty and exclusion in Australia. Bristol: Policy Press.

Saunders, P., \& Naidoo, Y. (2009). Poverty, Deprivation and Consistent Poverty. Economic Record, 85(271), 417-432.

Saunders, P., Naidoo, Y., \& Griffiths, M. (2008). Towards new indicators of disadvantage: deprivation and social exclusion in Australia. Australian Journal of Social Issues, 43(2).

Saunders, P., \& Wong, M. (2010). Poverty and Exclusion in Modern Australia (PEMA) survey.

Saunders, P., \& Wong, M. (2011). Measurement and Change in Deprivation and Exclusion in Australia; A report on research in progress. Paper presented at the Second Townsend Memorial Conference, University of Bristol.

Saunders, P., \& Wong, M. (2012). Promoting Inclusion and Combating Deprivation: Recent Changes in Social Disadvantage in Australia: Final Report (0733432301). Retrieved from Sydney:

Saunders, P., \& Wong, M. (2014). Locational differences in material deprivation and social exclusion in Australia.

Schwartz-Soicher, O., Geller, A., \& Garfinkel, I. (2011). The Effect of Paternal Incarceration on Material Hardship. Soc Serv Rev, 85(3), 447-473. doi:10.1086/661925

Scutella, R., Wilkins, R., \& Horn, M. (2009). Measuring poverty and social exclusion in Australia: A proposed multidimensional framework for identifying socioeconomic disadvantage. Retrieved from

Sen, A. (2000). Social Exclusion: Concept, Application and Scrutiny. Office of Environment and Social Development, Asian Development Bank, Social Development Papers, 1(June).

Shlafer, R. J., \& Poehlmann, J. (2010). Attachment and caregiving relationships in families affected by parental incarceration. Attachment \& human development, 12(4), 395-415. doi:10.1080/14616730903417052

Smith, A. (1776 / 1999). The Wealth of Nations Books IV-V. London: Penguin Books.

Social Exclusion Unit. (2002). Reducing re-offending by ex-prisoners (9). Retrieved from London:

Sykes, B. L., \& Pettit, B. (2015). Severe Deprivation and System Inclusion Among Children of Incarcerated Parents in the United States After the Great Recession. RSF: The Russell Sage Foundation Journal of the Social Sciences, 1(2), 108-132.

Targosz, S., Bebbington, P., Lewis, G., Brugha, T., Jenkins, R., Farrell, M., \& Meltzer, H. (2003). Lone mothers, social exclusion and depression. Psychological Medicine, 33(04), 715-722. doi:doi:10.1017/S0033291703007347 
Thoemmes, F. J., \& Kim, E. S. (2011). A Systematic Review of Propensity Score Methods in the Social Sciences. Multivariate Behavioral Research, 46(1), 90118. doi:10.1080/00273171.2011.540475

Thornberry, T. P., \& Krohn, M. D. (2001). The Development of Delinquency Handbook of youth and justice (pp. 289-305): Springer.

Thornberry, T. P., \& Krohn, M. D. (2005). Applying interactional theory to the explanation of continuity and change in antisocial behavior. Integrated developmental and life-course theories of offending, 14, 183-209.

Townsend, P. (1979). Poverty in the United Kingdom: a survey of household resources and standards of living. Berkely and Los Angeles: University of California Press.

Turney, K. (2014). Incarceration and Social Inequality: Challenges and Directions for Future Research. The ANNALS of the American Academy of Political and Social Science, 651(1), 97-101. doi:10.1177/0002716213501273

Watt, R., \& Sheiham, A. (1999). Health policy: Inequalities in oral health: a review of the evidence and recommendations for action. Br Dent J, 187(1), 6-12.

Wildeman, C. (2014). Parental incarceration and child wellbeing: An annotated bibliography. The Sills Family Foundation.

Wildeman, C., Schnittker, J., \& Turney, K. (2012). Despair by association? The mental health of mothers with children by recently incarcerated fathers. American Sociological Review, 77(2), 216-243.

Wildeman, C., \& Wakefield, S. (2014). The Long Arm of the Law: The Concentration of Incarceration in Families in the Era of Mass Incarceration. Journal of Gender Race and Justice, 17, 367.

Wilkins, R. (2015). The Household, Income and Labour Dynamics in Australia survey: selected findings from waves 1 to 12 .

Zilanawala, A., \& Pilkauskas, N. V. (2012). Material hardship and child socioemotional behaviors: Differences by types of hardship, timing, and duration. Children and Youth Services Review, 34(4), 814-825. doi:http://dx.doi.org/10.1016/i.childyouth.2012.01.008 
Table 1. Relationship with imprisoned male, percentage of caregivers

\begin{tabular}{lrr}
\hline Marital Status & $\mathbf{N}$ & $\mathbf{\%}$ \\
\hline Never married & 6 & 18 \\
Widowed & 1 & 3 \\
Divorced & 2 & 6 \\
Separated but not divorced & 4 & 12 \\
De facto relationship with the person who is in prison & 15 & 44 \\
Married, and living with spouse prior to him being in & 3 & 9 \\
prison & 3 & 9 \\
Married, not to the person who is in prison & 34 & $101^{1}$ \\
\hline Total & &
\end{tabular}

\footnotetext{
${ }^{1}$ Percentages were rounded to the nearest number, resulting in a total exceeding $100 \%$
} 
Table 2. Matching variables for the VF dataset, matched PEMA sample and PEMA general population sample.

\begin{tabular}{lccr}
\hline Indicator & VF sample & $\begin{array}{r}\text { Matched PEMA } \\
\text { sample }\end{array}$ & $\begin{array}{r}\text { PEMA (General } \\
\text { Population) }\end{array}$ \\
\hline Average number of children & 2.3 & 2.3 & 1.3 \\
Average number of adults & 1.2 & 1.2 & 2.2 \\
Average age (years) & 36 & 38 & 51 \\
Female & $97 \%$ & $95 \%$ & $57 \%$ \\
Unemployed & $18 \%$ & $25 \%$ & $2 \%$ \\
\hline
\end{tabular}


Table 3. Living condition indicators across groups.

\begin{tabular}{|c|c|c|c|}
\hline $\begin{array}{l}\text { Living Condition } \\
\text { Indicators }\end{array}$ & $\begin{array}{r}\text { VF Sample } \\
\%\end{array}$ & $\begin{array}{r}\text { Matched sample } \\
\%\end{array}$ & $\begin{array}{r}\text { General Population } \\
\%\end{array}$ \\
\hline $\begin{array}{l}\text { No } \$ 500 \text { in savings for an } \\
\text { emergency }\end{array}$ & 79 & $57 * * *$ & $21 * * *$ \\
\hline No telephone & 41 & $14^{* *}$ & \\
\hline No car & 29 & $11^{*}$ & $7 * * *$ \\
\hline $\begin{array}{l}\text { No week's holiday away } \\
\text { from home each year }\end{array}$ & 76 & 62 & $39 * *$ \\
\hline $\begin{array}{l}\text { Furniture not in } \\
\text { reasonable condition } \\
\text { No substantial meal at } \\
\text { least once a day }\end{array}$ & $\begin{array}{l}9 \\
6\end{array}$ & $\begin{array}{l}8 \\
2\end{array}$ & $\begin{array}{r}2^{*} \\
1 * *\end{array}$ \\
\hline $\begin{array}{l}\text { No decent and secure } \\
\text { home }\end{array}$ & 6 & 11 & 7 \\
\hline
\end{tabular}

Note. ${ }^{*} \mathrm{p}<.05 ; * * \mathrm{p}<.01 ; * * * \mathrm{p}<.001$ 
Table 4. Disengagement indicators across groups.

\begin{tabular}{lrrr}
\hline Disengagement Indicators & $\begin{array}{r}\text { VF } \\
\text { Sample } \\
\text { \% }\end{array}$ & $\begin{array}{r}\text { Matched } \\
\text { sample } \\
\text { \% }\end{array}$ & $\begin{array}{r}\text { General } \\
\text { Population } \\
\text { \% }\end{array}$ \\
\hline $\begin{array}{l}\text { Could not go out with friends and pay their } \\
\text { way }\end{array}$ & 51 & 62 & $18^{* * *}$ \\
Unable to attend wedding or funeral & 26 & 11 & $4^{* * *}$ \\
$\begin{array}{l}\text { Could not attend important event }- \text { no } \\
\text { transport } \\
\text { Does not participate in community activities }{ }^{2}\end{array}$ & 29 & $11^{*}$ & $4^{* * *}$ \\
No regular social contact with other people & 21 & 30 & $31^{* *}$ \\
No presents for family or friends once a year & 9 & 23 & 13 \\
Not accepted by others for who you are & 18 & 22 & 10 \\
Not treated with respect by other people & & 30 & 9 \\
\hline
\end{tabular}

Note. ${ }^{*} \mathrm{p}<.05 ; * * \mathrm{p}<.01 ; * * * \mathrm{p}<.001$

${ }^{2}$ The community activities referred to in the survey question are: education or school-based activities, a volunteer in health or community services, church groups or activities (other than attending services), arts, music or cultural groups/activities, sport (participant, volunteer or spectator), neighbourhood groups or activities of any kind, and a political campaign or event of any kind. The last response category was 'None of the above' and those who gave this response were identified as excluded on this indicator. See also 
Table 5. Service exclusion indicators across groups.

\begin{tabular}{|c|c|c|c|}
\hline $\begin{array}{l}\text { Service Exclusion } \\
\text { Indicators }\end{array}$ & $\begin{array}{r}\text { VF sample } \\
\%\end{array}$ & $\begin{array}{r}\text { Matched sample } \\
\%\end{array}$ & $\begin{array}{r}\text { General Population } \\
\%\end{array}$ \\
\hline $\begin{array}{l}\text { Unable to buy } \\
\text { prescribed medicines }\end{array}$ & 21 & 26 & $5 * * *$ \\
\hline $\begin{array}{l}\text { No access to dental } \\
\text { treatment when needed }\end{array}$ & 62 & 44 & $17 * * *$ \\
\hline $\begin{array}{l}\text { No access to a local } \\
\text { doctor or hospital }\end{array}$ & 6 & 0 & 4 \\
\hline $\begin{array}{l}\text { No access to bulk billing } \\
\text { doctor }\end{array}$ & 15 & 22 & 21 \\
\hline $\begin{array}{l}\text { No access to mental } \\
\text { health services if needed }\end{array}$ & 28 & 41 & 21 \\
\hline $\begin{array}{l}\text { No child care for } \\
\text { working parents }^{3}\end{array}$ & 50 & 46 & 41 \\
\hline $\begin{array}{l}\text { No access to bank / } \\
\text { building society }\end{array}$ & 9 & 8 & 6 \\
\hline $\begin{array}{l}\text { Unpaid gas water or } \\
\text { electric }\end{array}$ & 53 & 35 & $11^{* * *}$ \\
\hline
\end{tabular}

Note. ${ }^{*} \mathrm{p}<.05 ;{ }^{* *} \mathrm{p}<.01 ; * * * \mathrm{p}<.001$

${ }^{3}$ Was asked of all adults regardless of whether they were in work at that time. 